\title{
Restructuring Cameroon's Educational System Towards Ensuring Quality Education for Children with Visual Impairment
}

\author{
Charly R. Nyugap \\ Ph.D, Department of Educational Psychology, Faculty of Education, University of Buea, Cameroon
}

\begin{abstract}
Quality Education is a critical driver of the development agenda of any nation. In this era of global sustainable development and the quest for the attainment of Cameroon's development agenda Vision 2035, it is necessary that the Cameroon's educational system be strategically restructured to provide every citizen with the much-needed quality education for sustainable development. This paper thus examined the need for the restructuring of the Cameroon educational system towards inclusive education as a target of the Sustainable Development Goal (SDG) 4 - (Ensure Quality Education), from a critical disability theory perspective. Special focus was on the education of Children with Visual Impairment (CVI). Through the inclusive education innovation, CVI like any other group of special needs persons must be given due attention by the country's educational system. This is particularly necessary because of the peculiar nature of their educational needs. As bona fide citizens of the country, their educational challenges must be looked at from an inclusive lens, so that they can comfortably contribute to the nation building process, and the attainment of the global sustainable development agenda.
\end{abstract}

Keyword: Quality Education, Visual Impairment, Cameroon

\section{INTRODUCTION}

Education is a critical driver of the development agenda of any nation. In this era of global sustainable development and the quest for the attainment of Cameroon's development agenda - Vision 2035, it is necessary that the Cameroon's educational system be strategically restructured to provide every citizen with the much-needed quality education for sustainable development. Quality education here, is basically a process of strengthening individuals, organizations and communities with practical skills and knowledge, so that they canhave more control over their own situations and environments. A good quality education according to VVOB Education for Development (2016), is education that provides ALL learners with required capabilities necessary for; economic productivity, development of sustainable livelihoods, contribution to peaceful and democratic societies and enhancement of individual well-being. The learning outcomes that are required from quality education vary according to context, but at the end of the basic education cycle must include threshold levels of literacy and numeracy, basic scientific knowledge and life skills including awareness and prevention of disease. Capacity development to improve the quality of academic personnel and other education stakeholders is also crucial throughout this process.

In 2015, the United Nations adopted the 2030 sustainable Development Agenda known as the Sustainable Development Goals (SDGs). The 17 global goals are part of Resolution 70/1 of the United Nations General Assembly: "Transforming our World: the 2030 Agenda for Sustainable Development." Number four (4) goal of the SDGsfocuses on: Quality Education - Ensure inclusive and equitable quality education and promote lifelong learning. This is a unique goal that is purely on education and it happens to be the first time such a stand-alone education goal has been set and ratified globally (UNO, 2015). UNESCO, argues that obtaining quality education which is the anchor point of this goal, is the foundation to creating sustainable development. It emphasizes that quality education from the perspective of the 2030 development agenda, entails access to Inclusive Education that can help equip learners of all status with the necessary skills 
and tools required to develop innovative solutions to solve the world's greatest problems, which will implicationally improve the quality of life.

\section{What is Inclusive Education?}

Inclusive education is a placement option which admits learners or children with diverse backgrounds and learning needs into restructured physical and psychological environments to benefit from a restructured curriculum with the objective of giving all learners equal/equitable access to quality education. This is to enable each learner to make his/her unique contributions to nation building. UNESCO (2009), defines inclusive education as a process of transforming schools and other centers of learning to accommodate all learners including boys and girls, learners from ethnic and linguistic minorities, rural populations, those infected and affected by HIV and AIDS, those with disabilities and difficulties in learning and as well provide learning opportunities for all. To complement the above definition, UNESCO (2011) posits that; it is "a process of addressing and responding to the diversity of needs of all learners through increasing participation in learning, cultures and communities, and reducing exclusion from education and from within education."

The concept and philosophy of inclusive education gained international awareness from the 1990s, with the United Nations inclusion education conference in Thailand, promoting the idea of "Education for All". This was followed by the 1994 conference on inclusive education in Salamanca, Spain that led to the adoption of a policy statement proposing the development of educational systems with inclusive orientations as the most effective means of combating discriminatory attitudes, providing effective education for All learners/children, and ultimately improving the cost-effectiveness of the entire educational system (UNESCO, 1994).

\section{Children with visual impairment}

Children with visual impairment are among the category of learners to be captured by inclusive education innovations - a key target of SDG 4 on quality Education. Visual impairment is a refers to visual problems ranging from the inability to read print materials with or without the use of corrective ordinary lenses, to total blindness. Ozoji (2003), posits that persons with visual impairment are those whose sense of vision is defective - ranging from the ability to see a little, to total blindness. In addition to the above definition, Olukotum (2003) considers Children with visual impairment as those children whom after correction by all possible means, have such severe limitations in vision and use of it that they are limited in their education pursuit.

The belief behind the education of children with visual impairments is anchored on the principle of the equalization of opportunities and the premise that "education is a right and not a privilege". This position is supported by Ozoji (1999) and Nyugap (2017) who argue that the education of children with visual impairment is a right, meant to equalize for them and others, available opportunities in education and other services in a democratic and inclusive society. Consequently, whatever is achievable through the education of the sighted child, same should be achievable by the visually impaired. This philosophy can be successfully achieved through the provision of necessary human, material and financial resources within the educational system to include - personnel training, curriculum modification adaptations in instructional strategies, provision of special facilities, materials and equipment such as braille materials, training on orientation and mobility among others.

\section{The Problem at Stake}

An observation of the Cameroon's educational landscape reveals that a growing number of children with visual impairment are increasingly seeking access into the mainstream educational system. This new trend has led government to begin taking measures aimed at accommodating this group of special learners. Some of these measures include the adoption of some basic laws to protect the educational rights of children with disabilities in the country and the opening up of mainstream educational institutions to children of this category. However, the measures taken so far appear to be largely inadequate and theoretical than practical, even as the number of children with visual impairment seeking access to education continue to increase. Consequently, in a dispensation of quality education as advocated by the SDGs, there is need for appropriate and workable restructuring in major areas of the educational system to meet the quality educational needs of these group of learners.

Some of the targets of Goal 4 (Ensure Quality Education) of the SDGs further show the need for this restructuring: By 2030, substantially increase the 
number of youth and adults who have relevant skills, including technical and vocational skills, for employment, decent jobs and entrepreneurship; By 2030, eliminate gender disparities in education and ensure equal access to all levels of education and vocational training for the vulnerable, including persons with disabilities, indigenous peoples and children in vulnerable situations; Build and upgrade education facilities that are child, disability and gender sensitive and provide safe, nonviolent, inclusive and effective learning environments for all.

The attainment of the above targets especially at national level (especially in relation to meeting the needs of children with visual impairment) revolve around the restructuring of key areas in the educational system to incorporate among other things the inclusive education innovation. This is because children with visual impairments are among those with disabilities that have very peculiar learning needs that require adequate attention and such attention can only be effectively gotten through the deliberate restructuring of the mainstream educational system to inclusive setting where they can adequately and equitably compete with sighted peers (Nyugap\&Ngwa, 2015 and Nyugap, 2017).The major goal behind this inclusive education innovation is the hope that it is one of the main strategies to address the global challenges of marginalization, discrimination and exclusion, in response to the fundamental principle of quality Education for All. It gives every child or learner, including those with visual impairment and other special needs, the opportunity to learn comfortably in the same educational system or school environment, no matter their physical, social, and economic status (UNESCO, 2000).

The main objective of this paper therefore is to examine the education of children with visual impairment and somemajor areas for possible restructuring in the Cameroon's educational system, towards providing quality education for this group of learners, from the perspective ofSDG 4 (quality education) target on inclusive education. This is coupled with the necessity to make available information on the current issues relating tothe quality and evolution of inclusive education practices at all levels. It is only through such critical analysis of the prevailing situationthat a set of intervention strategies could be devisedto ensure the provision of quality education to the growing number of children with visual impairment within the Cameroon educational system.

\section{Theoretical Context of quality Education for Children with Visual Impairment}

Restructuring Cameroon's educational system towards ensuring quality education for CVI is theoretically underpinned by the critical disability theory and corroborated by the 2009 UNESCO inclusive lens model. The critical disability theory sees disability from the social model approach, which explains disability as a social construct rather than the consequences impairment. According to Hiranandani (2005) and Reaume (2014),critical disability theory views disability as both a lived reality in which the experiences of people with disabilities are central to interpreting their place in the world, and as a social and political definition based on societal power relations. Emerging from the activism of persons with disabilities (PwDs) in the 1970s, this area of critical disability involves both academics and activists representing multiple disciplines and perspectives. It challenges approaches that pathologize physical, mental and sensory difference as needing correction, and instead advocates for both accommodation, equity and equality for PwDs in all areas of life. Critical disability theory seeks to change conventional notions of PwDs as pitiable, tragic victims who should adjust to the world around them. This is a charity model, which is criticized for providing badly needed services without engaging the underlying causes of social exclusion. Barriers to education, employment, transportation and a host of services, both public and private, all come under the scrutiny of critical disability, a theory that works toward universal accessibility.

The critical theory of disability is all about the emancipation of persons with disabilities - in this case, CVI. Theory refutes the medical model that describes disability as a misfortune that can be prevented and cured or rehabilitated. Instead it prefers to acknowledge it and strives for equity, equality and inclusion. As far as the critical disability theory is concerned, the vital question is not whether a particular person is disabled or not, but rather what society's response to the person's circumstances will be (Pothier\& Devlin, 2006). The theory therefore plays an advocacy role in challenging discrimination in terms of disability, gender, ethnicity, and other exclusive tendencies (Goodley, 2013). Therefore, critical disability studies pursue solutions that ensure 
the full inclusion and participation of all citizens for nation building regardless of their physical, social, economic and political status.

In the struggle for the right of children with special needsor impairments to education and full participation in society, UNESCO, borrowing from the critical disability theory and the social model of disability, came up with the inclusive lens model. According to UNESCO (2009), the inclusive lens is a perspective of seeing the school or educational system as the cause of children's inability to attain their potential, rather than seeing the children as the cause. Initially, the blame was placed on the door steps of the children with disability. The inclusive lens model therefore advocates a shift from viewing the learners with disability as the problem, to seeing the educational system as the problem. The inclusive lens model believes in tackling the roots causes of these challenges as the overall solution to the problems of educational exclusion. Contextually, in an era of quality education for sustainable development, learners or CVI are not the cause of their educational challenges or their inability to receive quality education from the context of inclusion. From the critical disability theory and inclusive lens perspectives, it is the responsibility of the educational system - in this case that of Cameroon, to ensure that an equitable, inclusive and enabling environment is provided with the educational system at all levels to meet the needs of CVI.

\section{Brief history of the education of CVI \&government's policy responses in Cameroon}

The evolution of the education of CVI is rooted in the history of special needs education in Cameroon. Like any other educational history especially in the African continent, the history of special education could be traced from the pre-colonial to postcolonial eras. It evolved from informal otherwise known as indigenous education to formal education in these eras. Yuh and Shey (2006) and Nyugap (2017), affirm that the evolution of special education in Cameroon can classified under the pre-colonial, colonial and postcolonial periods. They argue that, it all started in informal settings of the pre-colonial era when some families of persons with special needs, especially those with disabilities taught them daily survival and interactive skills. Some of these skills include personal hygiene, communication, farming and craft work among others.
Around the late pre-colonial and colonial periods formal western education was brought into Cameroon through western missionary bodies notably the Baptist, Presbyterian and Catholic Missions. With this development, the education and care for children with disabilities became rooted in the community, church and charitable organizations largely under the auspices of the missionary bodies. According to Yuh and Shey the underlying objective of the missionary efforts to the education and care for children with disabilities was to ensure protection from exploitation and providing services which the public education and training system could not offer these group of children.

The postcolonial era, experienced an upsurge of specialized centers for the education of children and adults with disabilities mostly still by missionary bodies. Some of these centers which addressed the needs of CVI include; Rehabilitation Institute for the Blind (RIB), Buea, Cameroon Baptist Convention Integrated School for the Blind, Kumbo, St Joseph Children and Adult Home, Mambu-Bafut (SAJOCAH) (Yuh, 2003). According to Nyugap (2017), RIB was founded in 1967at Bavenga, a village in Muyuka by protestant missionaries, and was moved to Bulu, Buea a year later. In 1980, the Cameroon government in recognition of the need to develop the center and responding to the plight of the growing visually impaired population, decided to take over ownership and management of the institution according to Presidential Decree No. 80/38 of $13^{\text {th }}$ September, 1980. The center therefore became the first government-sponsored specialized center for the education and training of children and adults with visual impairment. The center has since then been under the administrative jurisdiction of the Ministry of Social Affairs (MINAS). Children in this center undergo training on the basic survival skills by children with visual impairment and are subsequently integrated into mainstream schools where they study alongside their sighted peers.

In terms of policy response, the Cameroon government in 1983, passed legislations such as Law No. 83/13 of July 1983 and recently Law No. 2010/002 of 13 April 2010 relating to the protection and welfare of Persons with Disabilities. The government also ratified international legislations on the protection of the rights of PWDs among which is the 2006 United Nations Convention on the Rights of Persons with Disabilities, which in its Article 24 
strongly advocates for the education of persons with Disabilities (SuhNgwa (2013), Nyugap\&Ngwa, 2015 and Nyugap 2017). Presently, an observational survey of schools around the country shows a good number of specialized centers for the education of children with special needs, and some regular schools that have integrated children with special needs within the main stream school system.

Sight Savers International, an NGO engaged in fostering the welfare of persons with visual impairment has been working in collaboration with the ministry of basic education on an inclusive education pilot program in selected schools within the South West Region of the Country (Nyugap, 2018). Some empirical findings have revealed a positive change in attitude among stakeholders towards CVI and increase awareness by members of the communities on inclusive education practices (Nyugap, 2015 and Fossoh, 2015). In the higher education domain, most of the state and private universities in the country admit students with special needs, but not in all the categories. The University of Buea is the only higher institution in the country that is known to be running an academic program in Special Needs education from Bachelor to Doctorate, aimed at training teachers and researchers for effective handling of persons with special needs in society, special and regular schools (Ngwa, 2012 and Nyugap\&Ngwa, 2015).

\section{Educating Children with Visual Impairment in Inclusive Educational Settings}

Vision, is one of the most important senses due to the important role it plays in the learning process. It is believed that more than $80 \%$ of education is acquired through the visual senses (Pagliano, 1994). Citing Lowen field (1983), Bhargava (n.d) held that blindness imposes three basic limitations on an individual in terms of:

$>$ Range and variety of experiences

$>$ Ability to get about

$>$ Control of the environment and the self in relation to it.

The extent to which a child is affected in these three areas will depend on the type and magnitude of the visual impairment; resulting in the child possessing unique educational and learning needs. According to Bhargava (n.d: 3), a student with visual impairment may lag behind in educational achievement in comparison to sighted peers due to the impact of visual impairment on learning. Consequently, the student will require skills to be specifically and explicitly taught, along with considerable additional time and opportunities to practice these skills. Some of these required skills as presented by Bhargave (n.d), Olukotun, (2003), Hannell, (2006), and Odle, (2009) include: developing an understanding of concepts, communication, social, orientation and mobility skills, the ability to independently participate in everyday life activities.

\section{Understanding Concepts}

Vision is the main sense that allows individuals to organize, synthesize and integrate information received from the environment to help us develop concepts about the world and how it works. In the absence of vision or in the situation of limited vision the individual often has to rely on the remaining senses of hearing, touch, smell, movement and taste to help assign meaning to the world. However, learning through the other senses is not always accurate and can sometimes result in a fragmented or partial understanding of the total concept. For example, feeling a raised outline of a plant is not the same like actually seeing the texture or size of a plant. This results in the visually impaired child developing concepts based on limited and fragmented information as he/she is unable to use the sense of sight to unify the different parts of the world and develop a complete picture of what is happening.

According to Odle (2009), blindness and visual impairment result in a limited ability to explore the environment. In the absence of vision or in the situation of limited vision, the child cannot see classroom displays or range of activity options in the environment. The student will need systematic instruction on how to explore the environment, given the time to explore it in a way that is meaningful. The development of spatial concepts is also affected by visual impairment. This includes the ability to develop an understanding of where the body is positioned in relation to the classroom environment (Is the student in the front, back, or middle of the room? What is the distance from classroom objects such as a bookshelf or the teacher's desk?) This further impact understanding of directions such as up, down, right or left, in considering space and distance.

Bhargava (n.d: 3) contends that sense of vision in humans gives information on how we look and how others look and interact. This information is then 
incorporated into our own interactions. Persons with visual impairments therefore use other senses such as touch and sound to gain this information, limiting the extent of their knowledge. For Lewis (2002, pp. 63), in Bhargava (n.d) exemplified that; knowing what one looks like by feeling one body part at a time may cause "difficulties understanding how all the different parts are related to each other". Also, considering that social appropriateness imposes restrictions on touching others. This inability of the individual with visual impairments to see others may provoke emotional responses and a sense of isolation.

Time concepts such as morning, afternoon, and night are learned through observation and use. For instance, a normal child perceives morning time and night time by seeing and making the connection between night time, associated with moon, stars, and dark environment, whereas morning equates with sun and light. For a child who is blind, understanding such environmental concepts is difficult because of limitations with visually associating the concept with the discussion. We might consider the difficulty of explaining the concept of clouds or stars or the moon in the sky to someone who is blind.

\section{Independent Living Skills}

According to Abosi and Ozoji (1985) Independent living skills include personal hygiene, food preparation, money management, time management, and skills related to organizing personal space so that it is easily accessible. For example, a child who needs to prepare tea for breakfast must first be familiar with the kitchen environment in order to locate the water, milk, sugar and other ingredients and utensils needed. The child needs to know the process involved in preparing tea and take to the dining table and afterwards wash and put things back in their original location. Children or learners who do not have visual impairment learn this incidentally by observing others. However, students who are legally blind are unable to pick up these skills through observation and need direct teaching of these skills.

\section{Communication Skills}

These areas include receptive and expressive language. Communication is developed by having a variety of experiences where the involvement is as an active participant or learning by watching others. Due to visual limitations, the student may have had a limited variety of experiences and missed out on incidental learning. This affects the student's understanding and expression. For example, a student without visual impairments who has never given a speech before but has watched peers present speeches would still have learned how to stand in the front of the classroom, face the audience, and speak in a loud voice. However, the knowledge of a visually impaired child giving a speech might be limited to someone talking about a particular topic, requiring direct teaching of such skills.

Often, CVI are unable to associate words with discussion topics. For example, a student who is blind or has low vision may be hearing what the teacher is saying but cannot associate it with the drawing that the teacher has made on the blackboard or a demonstration of how to carry out an experiment. This may result in the student using or appearing to be comprehending words without fully understanding them in the absence of vision, the student may have difficulty identifying the similarities between objects via visual information (Dunlea, 1989) and difficulty with categorization (Tobin, 1997). For example, the student may know that an apple is a fruit. Yet, knowing that bananas, pears, and oranges all belong to the same category although they do not feel, taste or smell the same is something that would need to be taught explicitly.

\section{Orientation and Mobility Skills}

CVI experience difficulties with creating a mental map or picture of their environment in order to figure out which direction to go or how to find their way round obstacles to reach their goals or destinations (A bang,2005). It is extremely important that children receive orientation and mobility training to develop concepts, skills, and techniques needed to travel safely, efficiently, and independently in environments. Orientation skills refer to the thinking skills involved in knowing where one is, in relation to the environment and the objects in that environment, and how to find the way to a particular destination.

Mobility skills involve the actual movement to the destination independently, safely, and with confidence (Pierangelo and Giuliani, 2007).For example, if students want to get from the classroom to the Principal's office, they need to first of all have a mental picture of the location of the principal's office, and be aware of the different clues or landmarks that they can use to independently get there. The accessibility of the assessment environment in public and none-public examinations is very important to the psychology and success of candidates with visual impairments. Consequently, lessons on how to keep in mind these 
skills need to be taught to get the visually impaired children acquainted with not only their learning environment but also the assessment environment.

\section{The Process of Educating CVI in Inclusive Settings} Identification of instructional needs of CVI is based on assessment results. Normally, before placement alternatives are discussed, instructional needs should be outlined as educational goals by an Individualized Education Program (IEP) team. It is possible and even likely that a child will have several needs within each area of the dual curriculum and that there will be numerous goals incorporated into the IEP. The needs of the student, and the educational goals established to meet those needs, should be determined without consideration of the environment in which those needs will be met. This is because despite the impairment, a student is the same person and has the same attributes no matter where instruction occurs. After a visually impaired student has been thoroughly assessed, his/her educational needs identified, and the instructional goals have been written, the Individualized Education Program (IEP) team then begins to address the question of placement. "Members of the placement team must ask themselves the question: "Where can all the goals identified for the affected learners be met?" If existing programs can meet most, but not all, of the student's needs, then alternative placements or the availability of supplementary services need to be explored" (Curry and Hatlen, 2007).

Learners or children with visual impairments will require some degree of interaction with sighted peers. Thus, it is necessary that this need is identified when determining the most appropriate placement for them. This is to allow CVI learn about their sighted peers and how to work and play with them. However, the fact that they need continuing contact with sighted friends, does not mean the best place to be educated is in an inclusive classroom. What is relevant is that the contact with sighted peers be meaningful for their cognitive and socio-emotional development.

The Virginia Department of Education in 2010 noted that inclusive or mainstreaming activities are of value when the visually impaired learners can fully and meaningfully participate in such activities. Meaningful participation signifies that the learners are provided with a foundation of academic and social skills that will provide an opportunity for success. However, to many visually impaired learners, this foundation of academic skills can best be acquired in segregated environments where all instructions are focused on their specific needs. A segregated school provides an emotionally safe arena to receive instructions and practice the social skills that sighted children learn through observation (IBE-UNESCO, 2007)).

Organized opportunities for successful mainstreaming experiences can therefore be more beneficial than constant peer contact with limited or no direction. For example, a blind second grade student who has mastered beginning braille writing skills and who has an adequate attention span might be appropriately mainstreamed into a spelling lesson in the regular classroom. In the course of receiving instruction in spelling, the student or pupil could also be developing and improving an ability to work with sighted peers: waiting one's turn, raising one's hand to ask a question, listening to a directed discussion, requesting other students to take notes, and working with the teacher to get accurate assignments, among other things (Forlin, 2010). According to Forlin, it might not have been the same case if this same student had been placed in the regular classroom for spelling instruction during the first grade (inappropriate placement). This is because; at this time there is still an inability to read or write braille with ease or to attend to a group lesson. Similarly, thissecond-grade student, even though mainstreamed for spelling, might be more appropriately placed in a segregated environment for instruction in another academic area, say arithmetic, and for instruction in other areas of the dual curriculum.

Consequently, the most appropriate placement for students or learners with visually impairments is a placement which allows for flexibility. Children enrolled at specialized training institutions for the blind need to have the option of attending mainstreamed or inclusive schools in order to receive instructions in those areas where there are reasonable expectations that they will experience academic success and social development (IBE-UNESCO, 2007). Also, frequent opportunities to interact with and recreate in the community must be provided to these learners. CVI enrolled in regular school programs need to have the option of instruction and training in a segregated environment for those areas of the dual curriculum that sighted children learn visually or which are unique to persons with visual impairments. Most important for these children (and 
often missing from their educational programs) are opportunities to meet with, and learn from other CVIand adults (Fuller et al, 2009).

\section{Major challenging areasin need of restructuring in the Cameroon Educational System}

Although the inclusive education innovation is one of the best indicators for success in quality education, turning inclusive strategies and requirements into reality appears to be a much more difficult task for policy-makers around the world (Sapon-Shevin, 2007) and especially in Cameroon where special and inclusive education is still pretty new to educational stakeholders. From the theoretical, conceptual and policy underpinnings of inclusive education in Cameroon examined in preceding paragraphs, we can critically identify challenging areas in the Cameroon educational system in need of restructuring towards quality education for CVI.

\section{Design of responsive \& contextual inclusive education policies}

The none existence of responsive inclusive education policies in the country is the major reason for the struggling take-off of inclusive education practices in schools around the country. Booth and Ainscow and Sandill (2010) suggest that barriers to inclusive learning and participation can be found in all aspects of local and national policies. There exists a wide gap between the few stated policies and standards and the practice of implementing them in mainstream or inclusive education settings. According to UNESCO (2010), inclusive education has been adopted as an important educational policy on the basis of social justice, equity and equality but it is unfortunately not being satisfactorily implemented in several developing countries, largely due to the absence of clear contextual and enabling institutional policies.

It is evident that policy frames the way institutional stakeholders think and ac. It is necessary that Cameroon government, as a policy restructuring measure does not only ensure that a comprehensive inclusive education policy is put place but such a policy must be responsive and contextual enough in order to shape the responses of education institutions towards the inclusion of learners or CVI in the country. As stated in the Salamanca Framework for Action (1993), educational policies should take into accounts both individual differences and contextual situations. In this regard, education institutions can act as catalysts for radical change in the promotion of the rights and full participation of CVI in all facets of society. Government must ensure that national and institutional policies and legislations recognize the principle of equal opportunities for people with impairments not only in education but in all facets of society (UNESCO, 1994).

\section{Provision of quality human, material and financial educational resources}

It is a believe within scholarly circles that most of the challenges to inclusive education innovation in developing countries (including Cameroon) are associated with inadequate human, material and financial resources. All these boils down funding of the educational system. Changes in none-funding policies without a change in funding policies, cannot be effective. It is through the restructuring of funding policies that all the resource requirements of educational institutions are met (UNESCO, 1994 and Stubbs, 2008). The lack of access to education for learners with visual impairments in most developing nations paints a negative picture of their education systems and hinged it on inadequate resources arising from inadequate funding or the mismanagement of the available meagre resources (Ainscow\&Sandill, 2010). The challenges in accessing the necessary human, material and financial resources are also associated with prevailing economic and developmental difficulties so that the provision of good quality education remains an unrealistic goal. Consequently, it becomes evident that the greatest barrier to the inclusion of CVI in these countries like Cameroon is limited resources, especially financial resources.

The provision of adequate resources is stated as a priority in the Salamanca Framework and considered as one of the most important requirements in the development of inclusive education. Considering the fact that a successful inclusive education system for with impairments depends largely on the availability of resources, it is that the Cameroon government makes provision for academic institutions to access the needed human, material and financial resources needed to upgrade the institutions. There is need for a restructuring in the funding and allocation of extra resources in the education sector needed for the purchase of adapted/assistive materials and logistics for both learners and teachers, hiring of professional teachers/ retraining of staff on inclusive education practices and the renumeration of staff (Wray, 2002,Sygall\&Scheib, 2005 and Stubbs, 2008).Institutional and political commitments are therefore needed to obtain additional human material 
and financial resources and to make the best use of those already available. One of the indicators of a good quality educational system for CVI is the presence of sophisticated inclusive resource and information centers in the different institutions. Consequently, apart from the government and other stakeholders making available additional resources, it is pertinent that visually impaired friendly resource and information enters be established to facilitate the education of CVI and other special needs in these inclusive settings; and ensure that such centers efficiently managed.

\section{Restructuring of Curriculums and instructional strategies}

Unless the curricula of the educational system are restructured to accommodate the diverse needs of learners with visual impairments and other special needs, inclusive education cannot be successfully achieved. According to UNESCO (2009), the curricula should be adapted to learners' needs rather than vice-versa. Such adaptation requires the analysis of what the educational system offers to learners and what is expected of learners with impairments (Powell, 2003). The modification must also be extensive, covering the subject matter, teaching methods/strategies and assessment process (Nyugap\&Ngwa, 2015). It is important to state that the educational system is all about the curriculum. That is, whatever is being done towards restructuring the educational system to quality standards, all count down to a restructured and adaptive curriculum that adequately incorporate the needs of CVI. The curriculum is therefore the major component of the educational system and often generate a greater proportion of challenges linked to content, organization and management of teaching, teaching methods and strategies, teaching/learning materials and equipment (Department of Education, 2001).

Children with visual impairment often experience difficulties when they are required to work with visual curricula materials presented as charts, diagrams and tables (McCarthy \& Hurst, 2001) that have not been adapted or modified. Also, the different learning styles of this group of learners are largely ignored in curricula design. Consequently, the lack of adjustments and adaptations to these curricula, instructional strategies and assessment become a major challenge for the impaired learners in inclusive settings (Wray, 2002). Restructuring the curricula and instructional methods is therefore a necessity.
Case studies reported by Powney (2002) reflect a variety of approaches to designing inclusive curriculums to widen participation in the education sector. Powney advocates that the first step in such curriculum design especially at the higher level is to identify the characteristics of prospective students. It is vital to understand the motivation and existing skills and knowledge that learners with impairments have on enrolment. In addition, when curriculum designers devise wider participation strategies, they should consider the needs students have before, and during their courses of study (Powney, 2002). The important thing here is that educators need to be flexible in their thinking about achieving the same goals by different means. For instance, one common area of need in curriculum modification for children with visual impairment is that needs are different and so study materials should be made available in alternative formats to serve the needs of all (SaponShevin, 2007). In this sense, an impaired learner does not only have the right to curricula and materials that have been presented in non traditional formats (e.g., printed text converted into Braille), but they also have the right not to be disadvantaged by the time taken in the conversion (Powell, 2003).

Karten (2010) argues that it is unfair to ask all learners in modern inclusive classrooms to achieve the same results if the methods of instruction are not varied and adapted to the needs of all learners. The best way to achieve this is to ensure that lessons are delivered in ways that are interactive, participatory and varied. The student-centered pedagogy recommended by the Salamanca Framework is a proven principle that can benefit all learners, avoid the waste of resources, and reduce the attrition rate in the educational system (UNESCO, 1994). It has been seen in practice that children with visual impairment require more instruction time and a wide range of instructional adaptations to address their unique learning needs (Meijer, 2001 and Nyugap, 2017).

Other areas in the educational system that needs to be restructured to inclusive standards apart from those discussed above include; ensuring accessibility of the physical environments in public or institutional infrastructures and also providing or strengthening support services where need be. For example, many impaired learners experience barriers to learning primarily owing to the system's inability to accommodate their diverse learning needs with enabling physical environments. Consequently, 
learners with visual impairment, are directly affected the in accessibilities of the physical environment (Uchem\&Ngwa, 2014). One of the typical physical barriers to inclusive education is the unavailability of ramps for wheelchairs in buildings and land marks to assist in the movement of persons with visual impairment (Wray, 2002).

\section{Conclusion}

Scholars have been able to establish a positive correlation between quality education and sustainable development. This is particularly true for nations that recognize the importance of education to the national development agenda. A critical look at the United Nations sustainable development agenda, shows education as the driving force to the attainment of this agenda. However, for that to happen, the inclusive education target of the educational goal itself (SDG 4 - Ensure quality education) must be given due consideration from a critical disability theory and inclusive lens perspective, particularly in relation to the needs of children with visual impairment. This paper has thus succeeded in examining the need for the restructuring of the Cameroon educational system towards inclusive education as a target of SDG 4, with special focus on the education of children with visual impairment. It is the believe of this researcher that children with visual impairment, like any other group of special learners must be given due attention by the country's educational system. This is particularly necessary due to the peculiar nature of their educational needs. As bona fide citizens of the country, they need to looked at from a critical disability theory perspective, so that they can comfortably contribute to the nation building process, especially in this era of thesustainable development agenda.

\section{References}

1. Abang, T. (2005). The Exceptional Child: Hand Book of Special Education. Jos: Fab Educational Books, Jos, Nigeria.

2. Ainscow, M. and Sandill, A. (2010). Developing inclusive education systems: The role of organizational cultures and leadership. International Journal of Inclusive Education, 14(4): 401-416.

3. Andzayi, C. A. (2002). Introduction to programs and services for children with special needs in Nigeria. Jos: Department of Special Education, University of Jos
4. Bhargava, D. (n.d). Teaching Students with Sensory Impairments: Definitions, Identification, and Supportive Professionals; Retrieved on $6^{\text {th }}$ June 2015 from: Www.trinity.edu/org/sensoryimpairments/VI/DIP/ VI_DIP_II.doc

5. Curry, S.A., and Hatlen, P.H. (2007). Meeting the unique educational needs of visually impaired pupils through appropriate placement. Journal of Visual Impairment \& Blindness. Retrieved on $16^{\text {th }}$ September 2015 from: http://www.eccadvocacy.org/section.aspx?TopicI $\mathrm{D}=451 \&$ DocumentID $=5282$

6. Department of Education. (2001). Education white paper 6: Special needs education: Building an inclusive education and training systems. Pretoria: Sol Plaatjie House.

7. Forlin, C. (2010). Teacher education reform for enhancing teachers' preparedness for inclusion. International Journal of Inclusive Education, 14 (7): 649-653.

8. Fossoh, M. (2015). The readiness of inclusive pilot schools for inclusive education practices in the South West Region. University of Buea: Unpublished paper

9. Fuller, M., Bradley, A. and Healey, M. (2004). Incorporating disabled students within an inclusive higher education environment. Disability and Society, 19(5): 455-468.

10. Goodley, D. 2013. Dis/entangling critical disability studies. Disability and Society, 28(5): 631644.

11. Hannell, G. (2006). Identifying children with special needs: Checklists and action plans for teachers. Thousand Oaks, CA: Corwin Press

12. Hiranandani, V. (2005). Towards a Critical Theory of Disability in Social Work. Critical Social Work, 6, 1-14.

13. International Bureau of Education and UNESCO. (2007). IBE-UNESCO preparatory report for the 48th ICE on inclusive education. Dubai.

14. Karten, T. (2010). Inclusion strategies that work. Thousand Oaks: Sage Company.

15. Meijer, C. 2001. Inclusive education and effective classroom practices. OstreStationsvej: European Agency for Development in Special Needs Education.

16. Ngwa, E.S. (2012). Inclusive assessment strategies by the Universities of Ibadan, Nigeria and Buea, Cameroon. Unpublished paper: University of Nigeria, Nsukka 
International Journal of Trend in Scientific Research and Development (IJTSRD) ISSN: 2456-6470

17. Nyugap, C. R. and Ngwa, S. E. (2015). Assessing the Satisfaction of Persons with Disabilities (PWDs) with Inclusive Education (IE) Practices in State Universities: The Case of the University of Buea (UB), Cameroon. African Journal of Special Education.

18. Odle, T. (2009). Visual Impairments: Assessment and Instructional Issues. Retieved $1^{\text {st }}$ June 2015, from:

http://www.education.com/reference/article/visual -impairments1/

19. Olukotum, D. (2003). Teaching Children with Blindness and Visual Impairments. A Basic Text: Codak Publications, Ibadan: Nigeria.

20. Ozoji, D. (1999). Selected Issues in Special Education. Jos: Deka Publications.

21. Ozoji, E. D. (2003). Special education: For beginner professionals $\left(2^{\text {nd }}\right.$ ed.). Jos, Nigeria: Enterprises Publications.

22. Ozoji, E. D. (2004). Attitudinizing the special education teachers. Journal of Special Education and Rehabilitation, 3(1), 21-25.

23. Pierangelo, R., and Giuliani, G. (2007). The educator's manual of disabilities and disorders. San Francisco: John Wiley \& Sons.

24. Pothier, D. and Devlin, R. (2006). Critical disability theory: Essays in philosophy, politics, policy and law. Toronto: UBC Press.

25. Powell, S. (2003). Special teaching in higher education: Successful strategies for access and inclusion. London: Kogan Page Limited.

26. Powney, J. (2002). Successful student diversity: Case studies of practice in learning and teaching and widening participation. Northern Ireland: Higher Education Funding Council forEngland.

27. Reaume, G. (2014). Understanding critical disability studies. CMAJ, 186 (16) 1248-1249; DOI: https://doi.org/10.1503/cmaj.141236

28. Republic of Cameroon, (2010). Law No. 2010/002 of 13 April 2010 relating to the education of Persons with Disabilities

29. Sapon-Shevin, M. (2007). Widening the circle. Boston: Beacon Press.

30. Stubbs, S. (2008). Inclusive Education: Where there are few Resources. Oslo: the Atlas Alliance.

31. Suh-Ngwa, (2012). Disability Laws in Cameroon and the Education of Persons with Visual Impairment (PVI). Unpublished M.Ed thesis: University of Buea

32. Sygall, S. and Scheib, M. 2005. Rights and responsibilities: A guide to national and international disability-related laws for international exchange organizations and participants. USA:Mobility International/National Clearing House on Disability.

33. Uchem, R. N., Ngwa, E. S and Asogwa, D. U. (2014). Inclusive Education and Sustainable Peace in Africa, International Affairs and Global Strategy, 19(48 - 54). Can be accessed at www.iiste.org

34. UNESCO, (2009).New UNESCO Guidelines on Inclusive Education. Paris: UNESCO.

35. UNESCO. (2001). Open file on inclusive education. Paris: UNESCO.

36. UNESCO. (2002). Examples of good practice in special needs education and community-based programs. Paris: UNESCO.

37. UNESCO. (2003). Open file on inclusive education. Paris: UNESCO.

38. UNESCO. (2005). Guidelines for inclusion: Ensuring access to education for all. Paris: UNESCO.

39. UNESCO. (2010). Inclusive education. Accessed on; 19/7/2010 from: http://www.unesco.org

40. UNESCO. (2011). EFA Global Monitoring Report: The hidden crisis - Armed Conflict and education. Paris: UNESCO.

41. UNESCO. 1994. The Salamanca Statement and Framework for Action on Special Need Education. Spain: UNESCO.

42. United Nations. (1994). Standard rules on the equalization of opportunities for persons with disabilities. UN General Assembly.

43. United Nations. (2007). Overview of international legal frameworks for disability legislation. Accessed on 04/5/2012 from: http://www.un.org.

44. UNO, (2015). Transforming our world: the 2030 agenda for sustainable development. United Nations General Assembly: New York

45. Wray, M. 2002. Modification of examination and assessment arrangements for disabled students: Additional support or added advantage? Manchester: Manchester Metropolitan University.

46. Yuh, E. N. (2003). A Report of Institutions Serving Persons with Disabilities in North West and South West Provinces of Cameroon (Unpublished paper)

47. Yuh, E. N. and Shey, P. F. (2006). The Education of Persons with Special Needs in Cameroon: A Historical Perspective. African Journal of Special Education 1(1), 27 - 31 